\title{
Desarrollo profesional en bibliotecología y ciencias de la información en una economía basada en el conocimiento ${ }^{1}$
}

\author{
ORLANDo ARboledA-SEPÚlVEdA \\ UniversidadNacional,EscueladeBibliotecología,Documentación e Información. \\ Apar ta do 86-3000. He re dia, Cos ta Rica. Tel.(506) 2725034 \\ E-mail:orledas@racsa.co.cr
}

La sen da de la ex ce len cia se ini cia cuan do las personas se exigen más a si mismas que a los demás

\begin{abstract}
RESUMEN
La economía basada en el conocimiento pone en evidencia que el desarrollo profesional es una responsabilidad compartidaentre las organizaciones ylos trabaja dores. Sin em bargo, és tos sonalfinal, los res ponsables de su pro pio des tino, los due ños de los me dios de pro duc ción (el co no ci mien to) y por tan to re cae en ellos mis mos la ma yor cuo ta de res pon sa bilidad en cuan to a su de sa rro llo pro fe sio nal. Se su gie re la ne ce si dad de una reingeniería de la educación a la luz de las tec nolo gías de los sis te mas de información, que apoye el aprendizaje continuo. Se señalan los desafíos que el trabajador del conocimiento debe enfrentar para mantenerse en el mercadoprofesional. Se ex plica elconcep todeeconomíabasada en el conocimien to y sehacela dis tin ción en tre for ma ción y de sa rrollo pro fe sional.Seofrecen es tra te gias bá sicas para elpro fe sio nalde biblio te cologíay cien cias de la in for ma ción con la in ten ción de lo grar su de sa rro llo pro fesionaly elapren dizajeperma nen te quelepermita en focarlas habilidades y las ac ti tu des ne ce sa rias para la vida eco nó mi ca y, de este modo, man tener su empleo.

Palabras clave: Economía de la información; Educación continua; Gestores de información; Sociedad del conocimiento.
\end{abstract}

\section{PROFESSIONALDEVELOPMENT IN LIBRARY AND INFORMATIONSCIENCES, IN A KNOWLEDGE BASED ECONOMY ORLANDO ARBOLEDA-SEPÚlVEDA}

\begin{abstract}
The pres ent knowl edge based econ omy makes clear that pro fes sional develop ment is a shared re spon si bility for both the or gani za tions and their employees. However, each individual is responsible for his or her own
\end{abstract}

1 Ela bo ra do en prin ci pio como ma te rial de en se ñan za para el cur so "Ges tión del Co no cimiento" 2003. UniversidadNacional.EscueladeBibliotecología,DocumentacióneInformación. He re dia, Cos ta Rica. 
fu ture, as the owner of the means of pro duc tion. A reen gi neer ing of the educa tional sys tem is re quired in or der to cope with the ad vances in in for ma tion tech nology and com mu nica tion sys tems. These ad vances would sup port the appropriate environment for continuing education within organizations. Some basic learning strategies are suggested to the library and information workers in order to help them achieve their professional development and maintain their employability in the framework of the demanding and competitive information society.

Keywords: Economics of Information; Continuing Education; Information Managers; Knowledge So ciety.

\section{INTRODUCCIÓN}

Fldoc torDee pak Cho pra en al gu nos de sus es cri tos ex pre sa la idea de que el me-

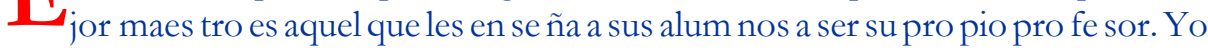
agre garía que quien lo gra esto re cibe una delas mayo res gra ti fi ca ciones de suca rre ra docente. Sobre el tema de capacitación y desarrollo profesional la literatura es amplia y su tra ta mien to es va ria do. Sin em bargo, el asun to se vuelve másim por tan te en el en tor noex plosivo dela era del co no cimien to. Prime ro dadala velo cidad, diversidad,complejidady turbulen ciadelcre cimien to delain formacióny elconocimiento, y en segundo lugar porque en nuestra sociedad los trabajadores del conocimiento, en particular, engrosarán cada vez más la población económicamente activa de nuestros países.

Una característica importante del trabajador del conocimiento es que su principal preocupaciónes dominarsuárea delsa ber, perocon siderán dolocomoparte de un todo quele permitees cogerlos mo men tos de ac tualiza ción, los mé to dosylas nuevasáreas de especialización. Este trabaja doryano seprepara con el fin debuscaryso meterseauna jerarquía organizacional, sino para participar como profesional en su área de especialización.Susconocimientosse conviertenen sucapitalde trabajo, su me diodeproduc cióny porlotantolagarantíadesuautonomíaparasuejercicioprofesional.

Desempeñar bien una profesión no significa que uno experimenta cambios importantes de carrera o se desempeña en diferentes instituciones a través de su vida profe sional.Más bienquie re de cirqueel pro fe sionaldebe es tarprepara do paraes tos cambioso, mejoraún, ¡para provo carlos! Quienes son exi to sos en el mun doactualde las orga niza cio nes y delas re des han te ni do que in cor po rara su dia rio viviruna re nova ción cons tante de sus habilida des, des trezas y actitu des, comositu vie ran siempre enmenteemprenderunanuevacarrera.

La primera hipótesis de este escrito es que no estamos del todo preparadospara afrontar la tran sicióna una era de man dan te de des trezas, ha bilida des yun con tinuo aprendizajequenos permi ta ejercerconéxitounaprofe siónenunentornocomplejo ydeinformacióncreciente. 
Lasegundahipóte sisesque eldesarrolloprofesional es un tema que aún no es muy bien comprendido, esto se percibe al menosenalgu naszonas de nues tra región anivel de es tudiantes delúltimoañodelacarreraydelos primerosañosdelejercicioprofesional.

Untercersupues to es queno hayuna de fini ciónyuna con cien cia cla rade a quiéno a quiénes les correspondeimpul sareimplemen tarlas acciones corres pondientes al desarrolloprofesional.

Es tos tres su pues tos han sido plan tea dos por el au tor con base en una ex ten sa experienciaanivelde AméricaLatina yelCaribe, en contactodirectoconins titu ciones y profe sio nales enáreas delain for ma ción bio-a grí colay am bien tal, y enla ob serva ción y discusión del tema con varias promociones dealumnos. ${ }^{2}$ El tema en sí no es nuevo pero ha toma douna di men siónes pecial da dosloscambios con tinuosen el entornopro fe sio nal. En el ambiente reinan telas ac tivida deseco nómi cas, en su ma yoría, se con cen tran en la crea ción, el pro ce sa mien to, la dis tribu ción y el uso de in formación. Es una economía moderna cuya productividad está centrada en el trabajo intelectualyenlaprestacióndeservicios.

Porelotrolado es el ca pital in telec tual el que en rea lidadles in te re saa las orga nizacio nes, ala aca de mia y alos in versio nis tas, pues to que es el re curso que hace a unainsti tu ción atractiva, ren tabley sos tenible. Es el re curso es tra tégico quecrea más riqueza y bie nes tar. Pero pese a su im por tan cia, to da vía es li mi ta da la aten ción que sele da en nues tros paí ses a lagerenciadelconocimiento, en ge ne ral, y al desarrolloprofesional en particular,comotemadeinvestigación,estudioyaplicación.

Lalite ra turaprofesional, sobretodoenlasáreasgerenciales, esabundanteporque estaresponsabilidadle corres ponde alasorga nizacio nes. Es cla roqueel temadeldesarrollopro fesionalno sóloatañealaprofe siónbiblio tecológicasinotambiénaotras dis ciplinas afines, porloque no es da ble, para los efec tos de este tra ba jo, re du cirla revisión de literatura al campo de la bibliotecología. Esto es más evidente cuando se trata de un mun do com plejo, cam bian te y com pe ti tivo don de esim pera tivo paralas empresascrearambientes dea prendizajecomopartedelaculturaorganizacional.

Senge ${ }^{3}$ señalaque enunmundointerconec tadoein terdependiente, conmercados altamente competitivos, con extremacomplejidad y gran dinamismoenlosnegocios, lages tión organizacional estávin culadaal cam bio permanen te y porlo tan toa su capacidad para apren der. A esto lo lla maorganizacionesinteligentesuorga nizacionesque aprenden. Peroés tas sólo pue den apren deren la me di daen quelo hace el perso nal dela orga nización, y en tanto en que estén en capacidad de integrar, comunicar y gestionar el

2 Básicamentees tudiantes debachilleratoylicencia turaenbibliotecologíaycien cias de la in for mación. UniversidadNa cional. CostaRica. Deigual manera se considera ronlas reacciones de las instituciones empleadoras sobre el tema del desarrollo profesional (Arboleda 1995, 2003). Observaciones sis temáticas realiza das porelau toren tre 1995 y 2003, lleva das a cabo en for ma directa, por estudios de diagnóstico para proyectos de desarrollo de uni da des de in formación, por análi sis de las reac cio nes de alum nos que a su vez de sem pañan fun cio nes pro fe sio nales, y no menos importante, la propia experiencia profesional en diversas organizaciones.

3 P. M. Senge, 1995. La quintadisciplina. Madrid. Granica.490p 
conocimien toad quirido. Paraquetalprocesodeaprendizaje organizacionalocurra, es indispensable que su equipo de personal sepa aprender a aprender. De esta competen cia sur gen en rea li dad to das las de más y poreso se la de no mi na la ma dre de to das las competencias o la competencia superior. En un mundo cambiante como el del conocimien to, no hay otro fac tor que sea tande terminan tey tan be ne ficioso comola técnicadeaprenderaaprender.

Nuestros profesionales en bibliotecología y ciencias de la información deberán serlíderesenla tran sición dela erain dus trial ha ciala econo mía delconocimien toy de los servicios, los cua les son los res pon sa bles de provo car cam bios den tro del nue vo paradigma educativo del continuoaprendizaje y la creatividad. Pero también deberándesempeñarfun cio nes de ca rác ter geren cialden tro del nuevopa ra dig ma dela de legacióndeautoridadydelagestióndelconocimien to. ${ }^{4}$

El objetivo final de este trabajo es señalarle al profesional joven algunas estrategias que le permitansermás competitivo, lograrun mejorde sem peñoy realización profesional y, por lo tan to, sermás fe liz. Es evi den te que no son es tra te gias nue vas, pero al me nos al au tor le han sido de gran ayu da en su ca rre ra pro fe sio nal. Final mente, se les ofrecen algunos comentarios complementarios basados en conceptos y aplicaciones de otros au to res so bre la fun ción delin telec to pro fe sio nal den tro dela organizaciónmoderna. ${ }^{5}$

\section{LA ERA DE LA INFORMACIÓN Y SU IM PAC TO EN LAECO NO MÍA Y EN LA EDUCACIÓN}

La erain dus trial está sien do sus ti tui da en nues tra re gión por la era de la tec no lo gía delos sis te mas dein for ma ción y delas co munica cio nes. Esto seeviden cia en la transfor ma ción que se está dan do en for ma glo bal, ra di cal y veloz, en las áreas del tra bajo, dela educa ción, ydela vida en ge ne ral. Las ge ne ra cio nes que con vergen en esta época debenenfrentar,entreotros,loscuatrodesafíos siguientes:

1. Laexplosión de información. A partir de lainven ción delaim pren ta de Gu ten berg, en 1457, se generó un cambio trascendental en la tecnología de la información, que provocó una reac ción en ca de na en cuan to a la ace le ra ción, en can ti dad y ca li dad delconocimien toaccesiblealahumanidad. ${ }^{6}$ La ex plo sión de la in for ma ción en la era actual de la alta tecnología se ha vuelto más compleja. La sociedad de redes que combina la telefonía celular, la comunicación electrónica por fibra óptica y

4 O.Arboleda-Sepúlveda,2003. “Iden tidadpro fe sional enla eco no mía delain formación: el pa pel delColegiodeBibliotecarios", en RevistadeBibliotecologiay CienciasdelaInformación (Orga no de di fut sión, Co le gio de Biblio te ca rios de Cos ta Rica), 17(1/2):6-23.

5 J.B. Quinn, P. An derson, S. Fin kels tein,2000. "Lages tión del in telec to pro fe sio nal: sa car el má ximo de los me jo res," en HarvardBusinessReview: Gestión delconocimiento. Bil bao, Es paña. Deus to.pp: 203-230.

6 G. Probst, S. Raub, K. Romhardt. K., 2001. Administreelconocimiento.México,D.F.Pearson Educación. 368p. 
por satélite, hace que la transmisión de enormes volúmenes de información sea casiinstantánea. Disponemosdeordenado res, videos, discoscompactos, yotros sistemas y dispositivos electrónicos de transmisión de datos.

Este in cre men to de la can tidad y di versidad de fuen tes de in for ma ción asícomo suvelocidad de transmisiónhacreado situa cio nes proble máticas enelsentidode que en frenta mos un excesocre ciente de da tos ein forma ción, en tan to que dis ponemos de poco tiem po para abor dar la yno es ta mos pre para dos, en tér mi nosgenerales, para utilizarla en forma productiva.

2. Elimpacto en la educacióny en el tra bajo. El po der del ce re bro ha su pe ra do a la fuerza físi ca como mo tor que mue ve la eco no mía de los paí ses. La edu ca ción formal así como una gran proporción de las ocu paciones, giran al re de dor, de al guna forma, del procesamiento y aplicación de la información y en la mayoría de los casos, tanto la edu ca ción como la pren sa ha bla da y es crita, los se gu ros, las finan zas, los servicios bancarios, el mercadeo, las agencias de consultores, los expertos en ciencias contables, los abogados, sociólogos y economis tas, los funcio na rios gut bernamentales, losprofesionalesdelabibliotecologíaydocumentación,etcétera, todos dependen en gran ma ne ra de la in for ma ción y de la tec no logía de los sis temas de información y comunicación.

Este giro de la eco no mía ha cia las pro fe sio nes ba sa das en el co no cimien to im plica que mu chas de ellas pue den volverse ob sole tas en muy cor to tiem po. Otras sut friránuna rá pi da trans formacióny exigirán que sus practican tes dominennuevas metodologías y adquieran conocimientos diferentes o más avanzados. Se refleja ya una distinción en tre quie nes ma ne jan y tie nen ac ce so a la in for ma ción y aquellos que ape nas so bre viven en laigno ran cia. Aquellos ba san su po dery su éxi to en el conocimiento. Son sus propios jefes y los dueños de sus medios de producción, es decir, del conocimiento.El conocimiento es el recurso que les permite a las personas tomar decisiones, emprender acciones en las áreas de los negocios, de la salud, del bienestar y de la superación personal.

3. El efectodelainfodiversidad. La com ple ji dad dela in forma ción se ma ni fies ta en la creciente diversi dad desus fuen tes, enlas di fe ren tes formas depresen ta ción, en la na turalezacambiante de su contenido,yenlos múl tiplesca nales de transferencia.Las nue vas ge ne racio nes, des de su más tiernain fancia, es tán más ex pues tas a es tos flujos crecientes de datos, información, experiencias, hechos, sentimientos, tendencias, etcéte ra, so bre el pasa do y el pre sen te, perotam bién so bre el fu turo. Estohace que elserhuma noseencuen treago bia do portanex ce siva carga de in formación. La sobrecarga de información hace casi imposible que uno llegue a dominar un tema, a tomar decisiones apropiadas, a estar al día y a entender o anticipar los cambios en áreas específicas del conocimiento. Lo que creemos saber hoy y tener lo por cier to pue de no ser de fen dible en un cor to tiem po y esto crea ría un grado de incertidumbre mayor al que mantenían generaciones anteriores. Somos cons cien tes de que gran pro por ción de lo que lle ga a nues tras men tes ha sido tratadoymo dificado porotras perso nas, sehamezcladoconopiniones, prejuiciosy 
condiciones que han podido des virtuarel sentidode talin formación. ${ }^{7}$ McCarthy ob serva ba a este res pec to que las nue vas ge ne ra cio nes ten drán que ser más ca paces deimaginarsu fu tu roodebe rán re flexionar sobreloquenece sitanaprendero bien mantener el ritmo con relación a los avances que afecten su vida.

4. Transformar la información en conocimiento. ¿Cómo emplear la información en la vida diaria?Elcrecientevolumendein forma ción puedepresionarnosydebilitarnoso puede sernos de gran beneficio y ayudarnos a adquirir sabiduría. Mientras que la información consiste básicamente de datos y hechos, el conocimiento consiste enin formación so brelacualsehareflexiona do, sehaex perimenta doyasimilado. Este tiene una relación directa con el pensamiento, la comprensión y la creatividad. Por estarazón siem pre en con tra remosque son eviden tes y previsibles cuantiosos volúmenes de datos y hechos, hay gran cantidad de información por doquier, pero los conocimientos suelen ser más escasos.

Es más fácil producir una masa de datos, hechos, opiniones y cifras, pero no es posible generar conocimientos en forma masiva o en serie. Éstos los crean las mentes individuales, extraídos de experiencias personales que separan lo que es significativo de lo que carece de importancia. Debemos, pues, tenerlasu ficien te capacidad, creatividad y voluntad para que las distracciones de la vida moderna no impidan dedicarle el tiempo suficiente a la reflexión.

\section{LA CAPACITACIÓNY EL DESARROLLO PRO FE SIO NAL EN LAERA DEL CO- NOCIMIENTO.}

Cualquier cosa que usted haga le podrá parecerinsignificante, pero es importante que la baga

Mahatma Gandi

Una eco no mía es un sis te ma para crear riquezay bienes tar, asícomoparalograrsu distribuciónapropiada. Tapscott ${ }^{8}$ señalabaquelanue va economía digitalestábasada en el capi tal hu ma no y enlas re des. Por tan to, en estaeconomía, el co no cimien to está presente en todo lo que es importante: personas, productos, servicios, empresas, proyectos, organizaciones.

Ennues tra regiónseobservaquelostrabaja do res delconocimien to al canzancada vezuna mayor pro porción dela fuerza la bo ral.Los sec to res dela eco no mía que utilizanlain forma ción en formain ten sivason losquegeneranmás fuen tes detrabajo. En esta economía, cada vez más, los trabajos basados en el conocimiento son los que másgeneran riqueza:elcerebrosuperaalmúsculo.Lamayorpartedela fuer za laboral

7 M. J. McCar thy, 1991. Domine la era de la información. Barcelona. Robinbook. 301p.

8 D. Taps cott, 1998. Creciendo en un entorno digital, la generaciónnet. Bo go tá, McGraw-Hill. 304pp. 
está constituida por quienes trabajan y producen más con sus mentes que con su fuerzafísica.

Losúl timos vein te años se han carac te riza do poreles ta ble cimien to cre cien te de instituciones de educación superior y en campos especializados diversos, tanto del sectorpúblicocomodelaini cia tiva privada. Comoconse cuenciase ha multiplica do laproporcióndejóvenesdiplomadosy deadultos preparados yes pecializados, pero queyaestándemandandooportunidadesyprogramasdecapacitacióncontinua.

Quienes hemos seguidodecerca el de sempeño delas orga nizaciones más afines con nues tra fun ción pro fe sio nal en Amé rica La ti na, nos he mos dado cuen ta que su valorhapasadodelos ac tivos físi cos alos ac tivos in tan gibles del conocimiento o capitalin telec tual. Esto suce de en la me di da en que para so brevivir, de sa rro llarse oteneréxi to, ta les orga niza cio nes se han vuel to más de pen dien tes de su co no ci mien to in ter no, de las des tre zas de sus fun cio na rios, de las re la cio nes con sus clien tes y provee do res, de la mo ti va ción de sus em plea dos, y de las in fraes truc tu ras que apo yan la creación, fortalecimiento y utilización del co no cimien to. Esta si tua ciónes cada vez más exigidaygenera liza da, porlo tan to el reto ma yor, para las orga nizacio nes, tanto delsec tor públicocomodelainiciativaprivada, será encon trarlas formas degenerar, atraer,retenery fortaleceresecapital in telectual.

Cada día sein si núa más una gene ra ción que co mien za a proce sar in for ma ción y a aprender de manera di feren te a sus an te ce so res.Lasherra mien tas ba sadas enla tecno logía delos sis te mas de in for ma ción les ofre cen opor tu ni da des para di se ñarotro modelo de aprendizaje basado en el descubrimiento y la participación, y no meramente enla transmisión de in formación. Laya crecien tein cur sión detalgeneracióna la fuerza la boralen nues tra re gión, em pie za a exi giry a for zar a las empre sas a es tablecerambientes propiciosparaunapren dizajecon tinuo.Deigualmaneraobliga ráalas auto ridadesacadémicas correspondien tes arepensarlanaturalezaylas funciones de laeducaciónyareplantearsuscontenidosysuformadehacerlaen tregaeducativa.

Sibien el sis te maedu ca tivo sigue sien do im portan te en la forma ción delos traba jadores del conocimiento, el sector empresarial y organizacional está demostrando mayorini ciativay dina mismoen estaárea so cial.Lacondiciónderápi da obsolescencia del conocimiento produce la necesidad de acelerar la velocidad del aprendizaje, como el mejor instrumento que tienen las organizaciones y las personas para crear ventajascompetitivasygarantizarsusostenibilidad.

Elan ti guo pa ra dig ma de la edu ca ción era que uno es tu dia ba de 15 a 20 años de su vida, yluego ejercía su pro fe sión has ta el mo men to de su re ti ro. Sin em bargo el para dig ma ac tual de "continuoaprendizaje", nos recla maqueya debe ríamoses tarpreparando a nues tras pró xi mas gene ra cio nes den tro de esa nueva con cep ción. En este sentido, comprendemos que el profesional deberá ser el "dueño de su propio futuro" y no necesariamentequesufuturoseráresponsabilidaddelasorganizacionesparalascuales eventualmente pueda llegar a trabajar. Sabemostambiénquelas organizaciones van a su frir cam bios, y que para mu chas de ellas su ciclo de vida será de ma sia do cor to oincierto.Segúnla revistaFortuneel $40 \%$ de las em pre sas que apa re cie ron en 1979, en 
re la ción con las ma yo res com pa ñías del mun do, ya no exis tían como en ti da des corporativasdosdécadasmástarde. ${ }^{9}$

En micaso par ticular, du ran telos úl ti mos trein ta años he tra ba ja do para cin co organismosinternacionales. Ningunodeellosestárealizandoprecisamentelas funciones paralas cua les fue ron crea dos; su es truc tu ra, ob je tivos, organiza ción y aun su visión han cambiado varias veces, y algunos luchan para apenas sobrevivir en un entorno cambiante y competitivo. Lo más curioso que experimentamos a este respec to es que sin cam biar de ins ti tu ción, de un mo men to a otro nos en con tra mos trabajando para una organización que no fue la que nos con tra tó años atrás, y que nos pide realizar funciones para las cuales ni ella ni nosotros estamos preparados. Este he cho eviden cia la necesidad de que el pro fe sio nal del cono cimien to deba de prepararse en forma continuada para mantenerse en el mercado laboral. Su ciclo de vida profesional pro me te seren adelan te más prolonga do que elde lasins ti tu cio nes para lascualessupuestamentesepreparóacadémicamente.

Drucker ${ }^{10}$ ob ser va que los in te gran tes de la fuer za de tra bajo y, más que todo, los trabajadores delconocimiento, ten dránquead minis trarsecadavez másasímismos, ubicarse en el lugar donde puedan hacer el mayor aporte, aprender a desarrollarse, apren deraman tenersejó ve nes y men tal mentevivos du ran tecincuentaaños devida la bo ral, y a sa ber cómo y cuán do cam biar lo que ha cen y a de ci dir cómo y cuán do lo hacen. Este autor continúa señalando que la vida laboral del trabajador del conocimiento, con las ac tua les ex pec ta tivas de vida en los países de sa rrolla dos, seráen promedio de 50 años. Sin em bargo, la ex pec ta tiva de vida pro me dio de las em pre sas exito sas es de sólo 30 años o qui zá me nos en pe rio dos de gran tur bu len cia, de bi do alos rápidos cam bios en el en tor no, los cua les les exi gen cam biar de rum bo o de én fa sis aunsinoestánpreparadasparaello.

En el caso de que las empresas sobrevivan tendrán que cam biarsu es truc tu ra, el trabajoquehacen yadquirirotrosconocimien tos, y prepararo em plearnuevopersonal.Estosignificaqueel trabajadordelconocimiento, enparticular, so breviviráa sus empleadores y tendrá que estar preparado para más de un empleo, más de una misión, más de una ca rre ray probablementemás deunidio ma. Estodeberálograrlo, en su mayor parte, por iniciativa personal. No le será tampoco conveniente esperar a quelasinstitucioneseducativasincluyantales cambiosen sus programasdeenseñanzaocon fiar plena men te en que las em presas paralas cuales trabajan es tablezcan ambientesdeaprendizaje.

Los trabajadores del conocimiento, en consecuencia, enfrentan retos y exigencias drásticamentenovedosastalescomo:preguntarseso bresusdeseosyas piraciones, sus

9 D. Tapscott, 1996. The digital economy: Promise end peril in the age of networked intelligence. New York. McGraw-Hill.

10 P. Drucker, 2002. Lage ren cia en la so cie dadfutu ra. Bogotá, Norma. 290 p. 
capacidades, sushabilidades, suposición, sucontribución, desarrollarsuinteligencia interpersonal, tenervisión desu futuro oun plan paralasegunda mitadde suvida. ${ }^{11}$

La crea tividad ylain no va ción se han convertidoen una ne ce sidad y no enunaopción. El capi tal in telec tual se ha con vertidoen el prin cipal re curso delas em presas, y en el me dio de pro duc ción del in dividuo. El ca pitaly la tec no logía de los sis te mas de in forma ción son fac to res esen ciales; sinembargo, no son su ficien tes para quelas organizaciones puedan sobrevivir y ser sos te ni bles en el mar co de la com pe ten cia actual. Encam biolain teligen cia em presa rial, el talen to delquedis pongaunaorga nización, su capacidad de innovación, y su velocidad de respuesta ante los cambios del en torno, no sólolespermitirá sercompe titivas, ren tablesy sos tenibles, sinotambién modificarlasreglasdeljuego.

\section{¿Formación o desarrollo?}

Según Jericó ${ }^{12}$ las empresas más admiradas, y podríamos agregar, los profesionales másexitosos, acu den más al de sa rro llo (tu torship = tu to ría oguia ; coa chingo men to ring = conseje ría oacto deinspirar) que a la for ma ción. El mo tivo es que eldesarrolloin ci de en lasactitudes, mien tras que la formación lo hace so bre los conocimientos. Elde sarrollode las actitudes permanece en un lugar de la memoria donde puede soportar mejor el paso del tiem po, lo que no su ce de con los co no ci mien tos apren di dos. Por ex pe riencia sabemos de cuántos conocimientosnos hemos desprendido ¡sin advertirlo! jlos hemosolvidado! ¡Cuántoscaducaronenelaula,elpropiodíadelexamen!

Peroeldominiodelosconocimien tos universitarios requieretambién elapoyode ac titudes tales como: trabajaren equipo, sabernego ciar, sercreativo ein novador, saberven derideas, lanzarse a come ter erro res y saberen fren tarlos, cultivarla con fianzaensímis mo, poderactuarconoptimis mo. Vivimos el mo men to cuan do la herejía estáconfrecuen ciamáscercadelaverdadquelasabidu ríaconvencional.

Eldesarrolloprofe sionalnonecesariamenteseconsigue, demanera formal, dentrodelsalón de clase, puedelograrseen el desempeñodelpues to re cibien doelconsejo, guía o ase so ría de al guien más ex pe rimenta do. Los re sul ta dos deldesarrolloprofesionalse advierten a mediano y largo plazo y no de inmediato como se supone que lo hace la for ma ción. Elau to de sa rrollo no se exige para de sem peñar un pues to, pero sî distinguealosmejoresen trelosprofesionalesydentrodelasempresas.

Drucker ${ }^{13}$ señala queeltrabaja dordelconocimien to debe sa tis facerdos nece sida desprincipales: educaciónformal, para te neracce so al tra ba jo del co no ci mien to, ylue go, educacióncontinuada du ran te toda su vida de tra ba jo, para mante ner al día lo apren dido. El conocimiento es diferente a las destrezas tradicionales, las cuales varían con mu cha len titud. Por tan to el adies tra mien to en des tre zas su po nía que lo que se aprendía en diezo doce años po día servirpara toda la vida. El co no cimien to, por el contrario,

11 P. Drucker, 1999.Losdesafíos de laadministraciónenelsigloXXI.BuenosAires, Sudamericana.229p.

12 Pilar Jericó,2001. Gestión del talento. Madrid. Prentice-Hall. 176 p.

13 P. Drucker, 2002. La gerencia en la sociedad futura. Bogotá, Norma. 290 p. 
rápidamentesevuelveobsole to, yeltrabajadordelconocimientodebe devolverar etomarsusestudiosconmayorfrecuencia.

Actualmente la educación continuada de adultos que ya poseen conocimientos especializados esac tual men teunárea de grancre cimien to, pero seim partedemanerasnotradicionales: seminarios de findesemana, talleresinten sivos, adiestra miento en servicio o "aprender haciendo", programas de capacitación en línea (desde una universidadoen eldo micilio deles tudiante), los mediosin formáticosfacilitanel autoaprendizajeylaintensificacióndelos colegiosinvisibles, etcétera.

Este mis mo au tor Drucker y el eco no mis ta de la Uni versi dad de Prin ce ton, Fritz Machlup, hacia1960, fue ron quienesidea ronlas ex presiones: industriadelconocimiento, trabajo del conocimiento, $y$ trabajador del conocimiento. Comprendersusimplicacionespara losvalores yel com porta mien to hu manoes dela ma yorim portan cia, sobretodo por aquellosqueintentan dirigiralos em plea dosyhacerlos produc tivosparala econo mía y la política.Drucker también des ta caen sus libros que en los países de sarrolla dos, el grupo de mayor crecimien to den tro dela pobla ción ac tiva, es el de quie nes tra ba jan conel co nocimien to, cuyo oficioles exige una edu ca ción su perior for mal. Unacaracterística de ellos es que se con si de ran a sí mis mos como pa res de quie nes con tra tan sus servicios, como pro fe sio nales y ase so res y no como sus em plea dos. Tam bién su conocimiento es eficaz y especializado, esto significa que necesitan tener acceso a unaorganización que reúna a otros ex pertos y aplique sus es pecializacio nes paralograrunobjetivocomún.

A este tipo de trabajadores han pertenecido tradicionalmente los médicos, abogados, eco no mistas, científicos y maes tros. Sinembargo, des pués delaSegunda Gue rra Mundial, un grupo mayor fue constituido por los tecnólogos. Éstos desarrollan trabajo manual pero también se les contrata por sus conocimientos adquiridos mediante la educaciónsuperiorformal.

Enlospaíses desarrolladoslostecnólogosmédicos constituyenelsegmentodela pobla ción tra ba ja do ra de ma yor cre cimien to enlasúl timas tres déca das. Dentro de este segmento se pueden mencionar también los asistentes sociales de psiquiatría, asistentesjurídicos, expertos en comunicaciones, diseñadoresindustriales, tecnólogos delain formación, com pu tación, manu fac turay educa ción.Los tecnólogosdelconocimientopro me tenser, a corto pla zo, elgrupo do minan te dela población tra baja do ra delospaísesdesarrollados.

En biblio te cología y cien cia delain forma ción se de sa rro lla bue na pro porción de trabajo no calificado como: el manejodelas comunicaciones, elprocesa mientotécnico y el archivo de documentos, el almacenamiento de publicaciones, la recuperación de documentos, el mantenimientode equipo e instalaciones, etcétera. No obstante lo que los identifica como profesionales en su propia estimación y en la del público en general, es la par te de su ocu pa ción que síim plicalage ne ra ción yla aplicacióndeconocimientosformalesasustareas. 
SegúnLevy-Leboyer ${ }^{14}$ si tra di cio nal men te se le ha dado gran im por tan cia a los títulos ydiplomasob tenidosporrazón de una for ma ción previa, el concep to de competenciao desarrolloprofesional ha en fa tiza do laidea de quela ex perien ciapro fe sionales el únicomediodeadquirircompetenciaso habilidadesnoreconocidasportalestítulos, pero cuyo evaluación obje tivase requie repara quelapersonapue dabene ficiarse de ellas y paraquela em pre saesté en con di cio nes de apro ve charlas. Esta preocu pa ción resultadelanecesidadderegis trarlascalificacionesdequienes solicitanempleo o una promoción y que poseen habilidades adquiridas mediante la práctica profesional, peroquecarecendeundiplomaquelas respalde.

Exis ten tres for mas de de sa rrollar las competenciasobabilidades: $1^{\circ}$ En la for ma ción pre via an tes dela vida pro fe sio nal ac tiva; $2^{\circ}$ A tra vés de cur sos de ca pa cita ción para adul tos du ran te la vida pro fe sio nal ac tiva; $3^{\circ}$ Porel ejercicio mis mo de la ac tivi dad profesional. Considerar útil la evalua ción de compe ten cias queno son re sul ta do de una for ma ción sino atribuibles a la ex pe rien cia re sul talla ma tivo por el he cho de que la vida ac tiva con lle va ex perien cias for ma ti vas, y de quela divi sión en tre un pe riodo en que se apren de y otro en que se uti li za lo apren di do es una no ción que ya no es deseableniaplicable.

Nunca se deja de apren der, oporlo me nos to das las ex perien cias son susceptibles de constituir ocasiones de aprendizaje. El aprendizaje, según los psicólogos, es un concepto bastante amplio. Va más allá de lo que corrientemente se cree que uno "hace al ira la es cuela". Elpro ce sode apren dizaje con ti núa todoel tiempo;portanto, una mejor explicación señala que aprender es cualquier cambio, relativamente perma nen te, que ocu rre como re sul ta do dela ex pe riencia. SegúnRobbins ${ }^{15}$ hay dos explicacionesparaelprocesodeaprendizaje,ladelineaciónyelmodelamiento:

1. Buena parte de nues tro apren dizaje pro ce de pordelineación. Probamos, fallamos y probamos de nuevo. O sea, por prueba y error casi todos dominamos destrezas como mon tara caballo, con tes tar exá me nes deop ción múl tiple o rea lizarope raciones matemáticas elementales. Muchosgerentes re fuerzanen formasistemáti ca esta for ma de apren dizaje porme dio de re com pen sas a cada paso del proce so que aproxima a sus empleados a la conducta deseada.

2. Mucho de lo que aprendemos resulta también de observar a otros y así modelar nuestro comportamiento según el de ellos. Este procesopuedegenerarcambios conductuales complejos con relativa mayor rapidez que el anterior. Esto sucede con frecuencia al observaryasimilarproce dimien tosy comportamientosdepersonas exitosas o admiradas.

El presente artículo pone énfasis en aquellas acciones de mejoramiento permanen te que el es tu dian tey el pro fe sional de ben pla neary eje cu tarporinicia tiva personal, independientemente de las políticas institucionales que apoyen su desarrollo profesional.

14 Claude Levy-leboyer, 2002. Gestión de las competencias. Barcelona. Gestión 2000. 161 p.

15 S.P. Robbins, 1998. Fundamentosdecomportamientoorganizacional.México,D.F.Prentice-Hall.303p. 
Desarrollo profesional es un concepto que ha sido tratado de alguna manera por la profesiónbibliotecológica y por sus asociaciones profesionales. Los colegios de biblioteca riosprofesionales des tacanen susestatutosquesumetaprincipalesproveerles oportunidades de desarrollo a sus colegiados para que amplíen su capacidad de ofrecermejo res servi cios y re cur sos de calidad. ¿Quées lo que se en tien de en ton ces pordesarrolloprofesional?

Gelfand ${ }^{16}$ destacaqueel términosede finecomúnmen tecomounaac tividadcuyo fines am pliar las habilida des del pro fe sional para de sempeñarlas funciones relacionadas con su trabajo. Esta autora ofrece además algunos ejemplos de actividades como:participarentalleresdetrabajo, seminarios yconferencias anivellocal, nacionalein ternacional; participaren cursos y programas de educación con tinuada;registrarse en cursos y ac tivida des aca dé mi cas; y for tale cerse a símismo a tra vés delabúsquedayconsultadeliteraturaprofesional.

Rockman ${ }^{17}$ am plíala lis ta con ac tividades tales como: laparticipación ac tivaen el trabajo con asociaciones profesionales; la elaboración y presentación de trabajos a congresos; la publicación de libros, artículos, reseñas, e investigaciones bibliográficas; la prepara ción de propues tas y proyec tos; la realiza ción de con sul to rías; el to mar licencias dees tu dio einves tiga ción; el realizarin tercambios de perso nal; yotras activida des que con tribuyana alcanzarun de sem peñoprofe sio nal queimplique unma yorgra do de co no cimien to y ha bilidad. Esta au to ra agre ga que este tipo de ac tividades de desarrollo profesional están ganando importancia entre los bibliotecarios de instituciones académicas, quienes esperan vincularse con estudios avanzados para asegurarsurenovacióndecontrato, garantizarseelpuestoolograrunapromoción.

Otros autores señalan que los programas de desarrollo profesional deberían incluirgra dos avanza dosenotras es pe cialida desodisci plinas, in ves tiga ciones poriniciativa y esfuerzopersonal, cursos cortoses pecializados, simposiosy programasde extensión.

Podría mos agre garque el de sa rro llo profe sio nal tam bién selogra al involucrarse dealgu na forma conel trabajodelos usuariosdelain formación. ${ }^{18}$ Por ejem plo, en las áreas bioagrícolas elexperto enin forma ción da se guimien to yapo yo ala formacomo tales especialistas manejan sus necesidades de información. Esto puede ocurrir en losproce sos degeneración, procesamiento, utilizacióny difusiónotransferenciade información,procesos que se dan en la estaciónexperimental, en elinvernadero, en

16 J.Gel fand, 1985. Pro fes sional de velopment for re fe rence and adult services libra rians. RQ (Summer):403

17 I.F. Rockman, 1989. Promotingprofessionaldevelopment:A localapproach. Colle ge and Re search Libraries News 50(11):902-904.

18 O. Arbole da-Se púlveda, 1990. "El cam bio en las pers pec tivas del uso delos sis te mas y servicios es pecializa dos dein forma ción en América La tina y elCaribe", en RevistaInteramericanadeBiblioteco logía (Colom bia)13(2): 61-81 y Arbole da-Se púlve da, O.2003. "La biblio te colo gía y cien cias de la in forma ción agrícola enla eco no mía de servicios, unanálisis den trodeun con tex toc ambian te", en Reunión Nacionalde Bibliotecarios, 37 ', Jornadade Bibliotecas Agropecuariasy Veterinarias, $10^{a}$. Bue nos Aires, Argentina. 14-17 abril, 2003. 15 p. 
ella bo ra to rio, en el aula de cla se, en la oficina, en el pro ce so de pre pa ra ción de materialde en se ñan zao en la pre sen ta ción de con tribu ciones para congre sos y re u niones olaelaboracióndepublicaciones.

\section{ÁREAS Y ESTRATEGIAS DE DESARROLLOPROFESIONAL}

Esinú tile bipócrita hablarmucho de crea ti vidad, pero conservarprocesos que matan la imaginaciónyelespíritu...

John Kao

Noparecieranece sarioinves tigardemasiadoparaverificarqueeldesarrolloprofesionalgenerabeneficios tan to paralapersonacomoparalasorganizaciones. Porlotan to paralograrundesempeño pro fe sionalapropiado, unodebedetenerex periencias de aprendizajecontinuasyasíreforzar, actualizarocomplementarsueducaciónformal.

Debidoalrápidocrecimien to del cono cimien to y delos avances tecnológicos, se estima que a 10 o 12 años de haber recibido su educación formal, la mayoría de los profesionales delabiblio te cología y cien cia de lain forma ción (BCI), se vol ve rán me nos com pe ten tes en com pa ración con lo que eran al mo men to de su gradua ción para desempeñarsuprofesión. ${ }^{19}$ Desdeluego estoes apenas un paráme tro, da tos que pertenecen auna ex periencia deun mo men to dado, algo di fícilde co rroborarcuantitati vamenteymuchomenosaplicablealejercicio profesionalde todosestosprofesiona les ensus diferentesambientes de trabajo.Sinembargo, es evidentelapercepciónyel sen tir de que el desarrolloprofesional es in dis pen sa ble en una era comola ac tual, de cambiospermanentes, discontinuoseimprevisibles.

Esta sec ción se pro po ne seña lar al gu nas áreas de de sem pe ño que se pres tan para lo grar undesarrolloprofesional.Pro bable men te no se ránlas únicas, pero sílas que es tán másalaccesodelprofesionalquedeseainiciarseenesteproceso. ${ }^{20}$

\section{La producción editorial, la enseñanza y la investigación.}

A medida que el profesional logra el estatus de profesor, investigador o alcanza posiciones de privilegioenáreas ge renciales, de be rácumplirdiferentes funciones y ofrecer servicios a la organización, y esto le exigirá diversas capacidades y conocimien tos. La ex pe rien cia de en se ñar es un ejercicio que en rique ce al com partirex pe rien cias, ya sea con los usua rios de la in for ma ción o en ac ti vi da des for males en las es cuelasdebibliotecología.

19 Rosie L. Albritton, 1990. "Continuing professional education: a management development approach". The Reference Librarian 30: 237-255.

20 - J.Martin,2001. "La crea ción de la cor po ra ción cibernética”, en Leer, Anne. Comp.Lavi sión de los líderes en la era digital. México, D.F., Pearson Educación. pp.324-332.

-White, G.W,2001. “The pro fes sio nal de velopment of re fe ren celibra rians:implica tions of research, publication and service”, en Ma bry,C.H. ed. Doingthe work of refe ren ce:practicaltipsfor excelling as a referencelibrarian. The Haworth Press, 2001. pp. 337-350. 
Loanteriorsereflejaalasumirres ponsabilidades docentes, elaborarmaterialesde enseñanzay presentardocumentos de trabajoo ponencias a congresosy elaborarput blicaciones formales. Las actividades de enseñanza, investigación y publicación incrementan laima gen pro fe sional como au tory ex per to en unárea del cono cimien to deinterés tan to en trelos colegascomoen trela comunidad. Consecuentemente esto au men ta también la repu ta ción eimagen delains ti tu ción parala cual tra baja esteprofesional.

Publicar constituye una contribución al campo académico y es una iniciativa que debe de ser propia e inherente a la condición de profesional de cualquier disciplina. Otro de los beneficios personales de la prác ti ca de es cri bir y publi car es que se in cremen ta la com pren sión y el do mi nio de las ten den cias y de lain ves tiga ción en su pro pia área.Setratadeunaoportunidadparadesa rrollarproyectosdeinves tigación másavanzados, peroestambiénunmedioparapermanecervisibleenelmercadoprofesional.

\section{Estrategias para iniciarse en trabajos de investigación}

Haymuchas estrategiasqueel profesional,particularmenteelque reciénseinicia, puede adoptar parainvolucrarseenun proyectodeinves tiga ción. Probablementelo másimportanteesseleccionaryconsultarlaliteraturapro fe sional.La mayorparte de ta les pro yec tos se da en áreas que ya han sido cu bier tas por otros. Se cons tru ye de alguna manera so brelos re sul ta dos dein ves tiga cio nes pasa das. La lec tu ray el análisis dees tu dios ac tuales, con frecuencia pue denin du ciralin ves tiga dor apen sary a decidirse por un proyecto de inves tigaciónque se puede basar en uno ya concluido o lo puedereforzarocomplementar.

La lectu racuidado sa delas directrices para sometertrabajosare vis tas, ofrecen el alcance de ma te ria, los tipos de tra bajos quese aceptan, y los procedimien tos formales que hay que seguir.

Unárea esen cialen el de sa rrollo pro fe sionales tra bajarbajo un men toroconsejero.Esto sig ni ficaque us ted realiza ac tivida des con el apo yo de un ex per to de am plia tra yec to ria en su cam po es pe cífi co dein te rés y que se preo cu pa por suavance. Tambiénse po dría tra tarde alguien que de mues tra un gran in te rés en am pliar, en rique cer y estimular el desarrollo profesional de otro miembro de la profesión. Esto es más corriente entre investigadores o consultores que recién comienzan su desempeño profesionalyportantobuscanelconsejoysuge renciasencamposespecíficos.

Unmen torpue de tam bién ayu darcon colecciones de da tos, sumi nis trarin forma ción sobre posibles revistas para publicar artículos y revisar y criticar trabajos para publicación. Un mentor no necesariamente trabaja en la misma institución, podría perfectamente pertenecer a una organización diferente.Investigadoresjóvenes podrían tambiénparticipar en equipos de trabajo o proyectos de investigación con un mentor. Untrabajoencolaboraciónconunprofesorouninvestigadorex perimenta do po dría con ver tirel pro ce so deinves tiga ción, pre sen ta ción y publica ción en algo menosintimidante. 
Escucharactivamentealos usuariosycolegascuandoofrecenserviciosespecializados de in forma ción pue de ser también unins trumen to para de sarrollarideas dein ves tiga ción.Lain te rac ción dia riayla discusión pue dengenerarvalio sos ein te resantes temas para investigación. Muchas ideas pueden surgir al participar en conferencias y escucharlasexposiciones, osimplementein teractuandoconcolegasdediferentesambientesyorganizaciones.

Elregistroylaparticipaciónenlis tas deex pertos, den trodesucolegio profesional a ni vello cal, o a tra vés de in ter net, tam bién pue den su ge rir tó picos de in te rés eideas parainves tigar ¿Quétipo de in for ma ción es la que másinte re sa a sus co le gas? Po dría serquelain formaciónquenecesitaunodeellospudieraservirleaotros.

La lec tu ra de ma te rial de otras áreas del co no cimien to a me nu do pue de suge riro gene rarideas y produ cirsolu ciones nologradas den tro desu cam po profe sional. En bibliotecología uno puede tomar como base un proyecto de investigación de otra dis ciplina y apli carloa pro ble mas rela cio na dos con lain forma ción. Estopo dría surgir en asuntos relacionados con segmen ta ción y es tu dios de merca do o en es tu dios sobreelusodelasdiferentes fuentesdeinformación.

Otra posibilidad para bus carideas es mirarlos anun cios de soli citud de ar tículos parapublica ción en las re vis tas es pe cia liza das o en los lis ta dos y te ma rios de fu turas reu nio neso con gre sos, de este modo co no ce ría las áreas y tipos de ma te riales so licitados. Pro fe sio nales a pun to de gra duarseo re cién egre sa dos podrían en con trareste material de gran interés parade sarrollarinves tiga cionesy ela bo rartrabajos para publicación, oparaprepararpropuestas de financia ción o pro yec tos de mejora mien to desusactividadesensupropiaorganización,oprepararinvestigaciones relacionadas consuprogramaacadémico.

Finalmente el profesional de la BCI puede animarse a publicar sobre las innovaciones que ha pues to en marchacomo partedesu trabajo profesional. Es cribirsobre tales ini cia ti vas y pro yec tos, dis cu tirel con tex to en que se dan enla li te ra tu ra profesional,es, paraelinvestigadorjoven, unbuenlugarparaempezar.

Una bue naprác tica a se guires ela bo rary mantenerun lis ta do de posibles tó picos para investigación y publicación. Este listado se irá elaborando y refinando con el quehacer dia rio. A su vez sele pue den agre gar, a cada tí tu lo, ideas, ex pe rien cias y bibliogra fía. Nocues ta mu cho hacerlo como una rutina pe riódicay mantenerlo enuna carpetaespecialensucomputadora. Deestaformaestarápreparadoparaaprovechar oportunidadesenelmomentoenquesepresenten.

Quienes no estén familiarizadoscon los métodos de investigación y con los instru men tos de recolecciónyanálisis deda tos pue denha ceresto yasea mediantelain tegracióndeequiposinterdisciplinarios, olaparticipaciónentalleresdetrabajoo con sultando manuales sobre métodos de investigación. También la práctica de la escritura, como todo, sevuelve más fá cil en tremás se prac ti que. Aun cuan do un tra bajole sea devuel toporuncomitéderevisión, cosaque puedeser frus tran te oin cómoda, tambiénes positiva.Loscomentarios delosrevisorespodríanseñalardeficienciasmetodológicas, 
fallas de redacción técnica o errores de presentación, así como sugerencias para el mejoramien todelacalidad, todolocual podría seraplicableenpróximos trabajos. ${ }^{21}$

\section{La participación en conferencias y presentación de trabajos}

Los congresos, reuniones y con fe ren cias de ca rác ter pro fe sio nal pue den ser una de las actividades más estimulantes para el campo intelectual. Las actas e informes que se presentan en es tos foros porlogeneralcu brentemas crucialesyáreas deinvestiga ción so brelascuales se ha publi ca do pocoy que es tán sien do obje toprio rita riode discusiónanivelnacionaleinternacional.

La participación en este tipo de eventos deja una cantidad deaspectospositivos. Probablementees ésta una de las mejores formas de actualizar se sobreprácticasinnovadoras, nuevos re cursosyáreas deinves tiga ciónde palpitanteinterés. Allísep resen taun am biente dein te rac ción con colegas y expertos en el que se pue den de sarrollar nuevas ideas para investigación y estudio, así como programas de capacitación, propuestasdefinanciaciónynuevasprácticasdemejoramientoprofesional.

La presen ta ción y dis cu sión de tra bajos en es tas re u nio nes ofre ce mu chos delos mismosbeneficios que se ad quie ren al ela bo rary publicarun ar tí cu lo en una re vis ta profe sio nal.Deestamaneraseincrementa o posicionalaimagendelau toryse asocia condeterminados cam pos dein te rés. También sepromuevesureputa ción pro fe sionalyla delains ti tu ción ala cual re presen ta. En mu chos ca sos tam bién se des ta ca por esteme dio sucole gio o aso ciación pro fe sio nal, alavezquese con tribuyealavancede lacarrera.

Lapre senta ción de ac tas, in formes yavan ces en es tas reu niones es una forma muy apropiada de poner a dis cusiónlos re sulta dos de es tudios, ex periencias einves tigaciones, ydelograrunarea limen ta ción rá pida paralos colegasyparticipantesinteresados. Lain forma cióncaptadamediantelainteracciónconlaaudiencia puedetornarse útil cuando se está elaborando un material para su publicación. En otras palabras, unopue dein tro ducirun ma te rialen suborra dor para dis cusión, queconlosinsumos adquiridosenlareuniónpuedefácilmenteserrefinadoyactualizadoparaserpublicado formalmente enunlibro o revis ta pro fe sional. También es tos asun tos así dis cuti dos pueden servir como trampolín para posteriores temas de investigación y desarrollode te sis o traba jos de gra dua ción. Final mente, mu chos dees tos forospublican sus tra ba jos como me mo rias, ac tas e in for mes, lo cual se cons ti tu ye en otro canal importanteparaautores queseinicianenestaactividadacadémicayprofesional.

\section{Estrategias para la participación en conferencias.}

La participa ción en con gre sos pue de seruna ac tivi dad one ro sa. Los cos tos deregistro,materiales y publicaciones, pasajes, alojamientoyalimentación pueden hacer

21 -O.Arboleda-Sepúlveda,1981. "Responsabilidadprofesionalenlaproduccióndela litera tu rabi bliotecológica", en Revista AIBDA 2(1):49-52.

-Arboleda-Sepúlveda, O.,1995. "Elproce so dere visión y edi ción de artículos para re vis tas deinterésprofesional”, en Revista AIBDA 16(1):86-99. 
de la participaciónalgo prohibitivo. La primera opción recomendada para la época ac tual de competen cia, cuyo nue vo pa ra digma es el con tinuo apren dizajey que elindividuo es responsable de su propio futu ro, es desa rrollarelhábi to de abriruna cuenta de aho rros que permita ali men tarese con ti nuo apren dizajey aprove charlas oportunidades que se presenten. Adicional a esto, es posible buscar posibilidades de finan cia mien to con su pro piains ti tu ción o conotras organiza cio nes a tra vés de ella. Otra opción es aprove charlas donacio nes opre mios que algu nasorga nizaciones (fflantrópicas, estatales, intergubernamentales, embajadas, empresa privada, etcétera) destinanaes tudiantesoprofesionalesreciénegresados.Lasescuelas debibliotecología, las asociaciones y los colegios profesionales deberían estar informados sobre estas fuentes, peroademás de berían convertirse enges to rasy ca nalizado ras de tales recursos.

Desde luego que es más fácil aprovechar las oportunidades cuando el candidato pue de cubriraunque seauna parte de los cos tos (comolaes ta día olos gas tos de viaje). Laparticipación en even tosins titu cionales olocales casinotienecostosy puederendirtambién resulta dos positivos, pero ade máses unabuenaoportu nidad deen trena miento inicial para participar más adelante, con mayor provecho, en reuniones nacionales e internacionales. Muchas instituciones que pa troci nan este tipo de reuniones, ofre cen financiamien to, parcialo to tal, aprofesionales queparticipencomo con fe ren cian tes opresen ten un trabajode base ovo lun ta rio al re dedordeltemacentraldelaconferencia.

Unprofe sio nal con poca ex periencia en participación en reu nio nes y en presenta ción de trabajos podría aso ciarse con su profesor, conse jero, unmentorounespecia lista con ma yor tra yec to ria tan to en la ela bo ra ción de tra ba jos como en su presen taciónoraly es crita. Estaop ción presen ta varias ven tajas porque secombinandiversas técnicas de apren dizaje: es una forma de apren derhacien do; se apren de porob serva cióno mo dela ción, y tam bién a tra vés dela dis cu sión so bre te mas es pe cíficos al recibirobservacionesysugerencias.

Unadelas mejores formas degene rarideas para elabo rarponen cias a congresoses mediante la lectura de los programas promocionales que solicitan contribuciones. Los te mas de estos programas pueden que dar registrados fácilmenteensu computa doray te nerlos us ted a mano parabus carliteratura eir ela bo ran doborrado res quele permitanes tarpreparadoparaunaeventualparticipaciónen congresosoreuniones. NormalmenteestosanunciosaparecenenlasrevistasprofesionalesoporInternet.

Lamayo ríadelosorganizadoresdeconferenciassolicitaninicialmenteeltítulo del trabajoyun re su men. Si eltrabajo es acepta do, se es pera quelos au to res es tén lis tos a prepararlo.Losautoresoparticipantespotenciales node berían serdema sia dovacilan tes pues to que es tos tra bajos no sue len ser tan ex ten sos y su ela bo ra ción no de bería to marun tiem po exage ra da men telargo. Ade más, lo peorque po dría pa sares que eltrabajofuerarechazado.

Sin embargo este conocimiento adquirido por la participación en reuniones no tiene valor si no se comparte. Conocemos un sinnúmero de casos de profesionales 
queviajany participan sis te má tica men te en este tipo de even tos, pero cuya con tribur ción a la profesión es muy pobre. Más bien es contraproducente porque de este modo se priva departici para colegasque sí pue den asi milary aportarmás a sus organizacionesyalaprofesiónengeneral.

\section{Actividades de servicio público o social}

Cuandosehabladeserviciopúbliconosrefe rimosaparticiparencomitéslocales, estatalesonacionales. Elservicioenco mitéslocalestalescomo comitésinstitucionales o regionales, le permite al pro fe sional en BCI ejer cer una voz di rec ta y cau sar un impacto en las operaciones locales dentro de su propia comunidad. En ocasiones este tipo de participación podría to marlas ca rac te rís ticas de las rela cio nes públicas. Aligualque su ce de conla in ves tiga ción y las con fe ren cias, con el servicio so cial también es posiblein cre men tarla visibilidad y man te nerunaima gen pro fe sionalen todos los asuntos relacionados con la profesión. En el ejercicio profesional siempre hay la posibilidad de in te rac tuarconmu chos fun cio narios y miem bros ac tivos dela ins ti tu cióno delaco munidad, y porlo tan to seestá enunapo sición privilegia dapara sabersobrelas diferentes face tas delosasun toslo cales oins titu cio nales. Esteconocimiento le da al profesional suficientes méritos como para integrar un comité, un equipodetrabajoounajuntadirectiva.

Lasorganizacioneses tatales ynacionaleslepermitenalprofesionalcausarunma yorimpac to consudesempeño.Los comi tés aniveles tataly na cio nalcon frecuencia serelacionan conac tivida des y progra mas educacionales parabeneficiarasus miembros, y los miem bros de los co mi tés in flu yen so bre lo que se ofre ce. El servicio enlos comitésaestos nivelestambiénproveeuncre cienteestatusy visibilidad profesional, y permite la interacción con los colegas de otras organizaciones. Estos contactos profesionales con tinuamentepruebanserútiles enunavarie dad depropósitos, tales comoconocersobrenuevosrecursos, programas, inves tigacionesen marcha, opara realizaractividades relacionadascon su profesión.Perteneceraasociacionesprofesionales ofrece el privilegio de votar y, consecuentemente, otorga una voz sobre cómodebeoperarlaorganización.

\section{Estrategias para iniciar las actividades de servicio público o social}

La mejor recomendación para involucrarse en actividades de servicio social es a través del voluntariado. Existen muchas oportunidades que este profesional puede aprove charparalograrinvolucrarse, además de mu chos comités, equipos detrabajo y pro yec tos que re quie ren per so nal ca pa ci ta do, con ideas y bue navolun tad para tra bajar. Anivellocal,probablementeesmejorparticiparentalesreunionesiniciamentecomoobservador. Enesta con diciónin clusoesposible suge rir temas o mejo rarlos que es tánenlaagen dapara dis cusión. También se ria re comen dableen trarencon tacto con el pre siden te del co mi té o de la Jun ta di rec tiva, an tes o des pués de la re u nión, para ofrecerle sus servicios voluntarios, estrategia que podría ser muy apropiada. 
Asis tira es tas re u nio nes es ade más una ex pe rien cia va lio sapara quie nes no hanvivido una experiencia similar. Revisar las actas o memorias de las reuniones, escuchar con detenimien tolas in te racciones y dis cusiones, apren derlospro cedi mien tos ylas normas parlamentarias, le añadirá un conocimiento de gran valor a su desempeño profesional.

La participa ción en este tipo de co mi tés, que seinicia volun ta ria men tey porini cia tiva personal, le conviene a veces a la propia institución por razones políticas y de ima gen, y por lo tan to es po sible lo grarsu apo yo ofi cial, lo cual le per mi ti ráalin teresadomáslibertadyseguridadparadisponerdeltiempoyelapoyologís ticonecesario.

Este tipo de participación voluntaria se puede iniciar desde la época estudiantil, preferiblementehaciafines desuetapa dees tu diouniversitario.Loscomités siempre están necesitandopersonal para desarrollar diferentes activi da des y tal veznoles es posible contratar a alguien. Esta participación, por iniciativa personal, se convierte enun trampolínpara hacerse conocer, realizar prácticas de tipo pro fesio nal, de mos trar sus conocimientos y habilidades, relacionarse con otros expertos en diferentes áreaseiniciardes demuytemprano suincursiónenelmercadoprofesional.

En trelasáreas enlas cualespuedeusteddesa rrollarsusprácticasestán:conocimiento y aplica ción delas nor mas parla men ta rias en las re u nio nes de trabajo; re dac ción de in formes y ac tas; ase so ría en la selec ción de ba ses de da tos yotras fuen tes de con sul ta; dominio delas téc ni cas para con du cir re u niones de trabajo. Y también podría co ordinar talle res de dis cu sión; servir como tra duc toro in ter pre te si tie ne al gún do mi nio de idio mas; asesoraren el de sa rrollo debases de datos; participaren foros de discusión en sesiones cul turaleso de divulgación en medios de comunica ciónsocial talescomoen la redacción de columnas periodísticas o en programas televisivos; integrar equipos de trabajoconcolegas deáreas afinestales comoco municadores, informáticos, maestros, publicistas,etcétera.

\section{COMENTARIOS FINALES}

Más que conclusiones pareciera más bien necesario agregar algunas observaciones que com plementan y acla ran con cep tos o de al gu na ma ne ra re fuerzan, lasideas, actividadesyexperienciasexpuestaseneldesarrollodeestetrabajo.

\section{Comentario 1}

La reproducción del conocimiento en las organizaciones es una forma de verificación cen tralizadacuya fun ción es dis tribuir, cuan to an tes, ciertosactivos delconocimiento en trelama yor parte de sus funcionarios. El nuevo cono cimien to sedebehacerconocerdeinmediato, en formaduradera, a todos losempleadosinvolucrados. Estose hará, porejem plo, con quie nes tra ba jan fue ra de las ins ta la cio nes, para la im ple menta ción de una nue va tec no lo gía o el re em pla zo de un soft ware. Pero tam bién, po dría hacerse a tra vés de talle res rela ciona dosconcambiosenlains titu ción, al ins truir a los empleadossobreunanuevadirecciónestratégicaparaunaunidadodepartamentode 
la organización. Tales procesosdereproducciónydistribucióndelconocimientose justificancuandoocurrenbajounadireccióncentralizada.

Por otro lado, las redes de conocimiento funcionanbasa das en principios descentralizados. En lugar de proporcionar acceso permanente a un capital de conocimiento pre pa ra do con an ti cipa ción, éste se brin da a me di da que sea ne ce sa rio. Este tipo de distribución exige condiciones en las cuales el conocimiento se suministre 'justo a tiem po', y se basa en la circula ción o en su trans fe ren cia en tre fun cio na rios a travésde lasinfraestructuras delareddeconocimientodelaorganización.

Este con cep tode re produc ción del co no cimien to se empleaen dos áreas cla ves de la actividad organizacional: la socialización, y el proceso permanente de capacitación y educación. ${ }^{22}$ La so cia liza ción se re la ciona con la ac ción de fa mi lia rizar a los em plea dos con laspolíticas, normasyvalores delains titución, además decomunicarleslas ex pectativas de los comportamientos y las funciones. Es decir, significa instruirlos sobre la cultura institucional. El propósito de la socialización podría ser presentar a los empleadosnuevosdentrodelainstituciónotransmitirlesuna estrategianueva.

En su for ma más sim ple, la socia liza ción preli minarocu rre me dian te el con tac to en tre compañe ros y susintercambios in formales so brela forma ha bitual de trabajar den tro dela em presa. Pero tam bién pue de darlugarala rea liza ción de talle reso se minariosendondeseenseñenlas bases delacul turacorporativa.

El conocimiento profesional también se pue de di fun dir me dian tela re pro duc ción del conocimiento. Las aptitudes del personal se deben mantener en un alto grado, en particular,enlas em pre sas diná micas quetienenunuso in ten sivodelcono cimien to. Lacapacitaciónprofesional es parte del de sa rrollo de los em plea dos. De esta for ma cada funcio na rio se po dríaca pa citaren el año, a me di da que fue ra nece sa rio y du ranteun periodo prudencial, por ejemplo,para aprendersobrelautilizaciónde nuevosins tru mentosdetrabajoosobrelasnuevasestrategiascompetitivas delaempresa.

Laprác ticaan te rior es di fe ren te a lo que ve mos con fre cuenciaen nues tros países, endondelos funciona riosparticipaneneven tos deformain discriminada, sinningún plany sinobe de ceraun propósi toins titu cional, y cu yos cono cimien tos nise aplican nisecompartenen formainme diata. Aveces estaprácticasehains titucionalizado en forma equivocada e ineficiente, en el sentido de que siempre hay un presupuesto anual que se debe de utilizar y agotar, pero no siempre esta capacitaciónla recibe la perso naapropia da oquienes en realidadaplica ránlosconocimientos alasáreascríticasdela organización. Porlogene ral, a talespersonas tampocoseles exige compartir losconocimientosadquiridosconelpersonaldelaempresa.

\section{Comentario 2}

La tecnologíadelossistemasdeinformacióny comunicaciónhace una con tribucióninnovadoraalain fraes tructuraeduca tivay al desarrolloprofesional.En este sentido nos permite

22 G. Probst, S. Raub, K.Romhardt, 2001. Administreelconocimiento.México,D.F.PearsonEducación. $368 \mathrm{p}$. 
incursionarennuevasposibilidadesde accesoalconocimien to, nuevosmétodos de procesamien to dein formación, y formas diferentes de apren dizajequein cluyenma yorautonomíayadaptabilidadalasnecesidadesindividuales.

El desarrollo profesional puede tomar la forma de diferentes y variadas actividades. Éstasincluyencursos formalesdeeducación continuada, seminarios, investigación, publicaciones y participación en el servicio público. Parece haber un sentir general entrelaprofesión, dequelas actividades de desarrolloprofesional sonbenéficas y deseables, sobre todo en la época actual dentro de la denominada economía de servicios. Sin embargo, prevalece una idea no muy clara de si esta responsabilidad recae so bre la per so na o so bre las or ga ni za cio nes para las cua les tra ba ja. El análi sis de las fuentes másactualessobreeltemasugiereuna mayor responsabilidad ycompromiso ins titu cional porelde sarrollopro fe sional, pues to que esto le ga ran tiza ala organizaciónsucompetenciaysostenibilidad.

Lalitera turagerencial recienterefleja notablescontribucionessobreunnuevop aradigmaen las organizacio nes. Para George Gilderensulibro, Microcosm:thequantum revolutionineconomicsandtechnology, el even to principaldel siglo XX fuepo nerla ma te ria ensegun do pla no. Al consi de rarla tec nología, la eco no mía yla política delos países, la riqueza enla formadelos recursos físicos de clinaen formasos tenidatan to envalor como en sig ni fica do. El po der dela men te so bre pa sa en to das par tes la fuer za bru ta delascosas. ${ }^{23}$

La revolución de la tecnología en los sistemas de información y comunicación permi telograruna trans forma ción signi fica tiva en los campos edu cativos ydecapa cita ción. Es tasáreas re vis ten ya una im por tan cia su perior dado que vi vi mos en una economía basada en el conocimiento. La contribución más importante que hace la tecnología delos sis te mas de in forma ción parala edu ca cióny la ca pacita ción, es abrir diferentes posibilidades de acceso al conocimiento, nuevos métodos de procesamientoymanerasalterna tivas deaprendizajemásau tónomas, flexiblesyadaptables a lasnecesidadesin dividualesydelosgrupos.Loante riortambién escomplementario alaeducaciónin formalen elhogar.

\section{Comentario 3}

Alcomienzodeeste trabajomen cionamos cuatro desafíosque de bemosenfrentarlosprofesionales o trabajadores del conocimiento. También advertimos que no estamos preparados para en frentartalesretos. Nues trossis temas edu ca tivosno hande sa rrolladoen el estudiante las actitudes mentales necesarias, ni les han suministrado las técnicas que se requieren para enfrentar la naturaleza imprevisible y cambiante de la era del conocimien to.Sinembargo, consideramosqueaún noesdemasiadotardeparadeci dirnos a crear hábitos y téc nicas quenos ayu denaafron tarlos de sa fíosimpues tos por laeradelain formación.

23 M.L. Ray, 1993. "Surgi mien to del nue vo pa ra dig ma en los ne go cios", enRenesch, J. ed. Nue vas tra di ciones en los negocios. Mé xi co, D.F., Pa no ra ma Edi to rial, pp. 39-51. 
Latradicionalenseñanzamemorísticanonoshapreparadoparautilizarelcerebro enunaproporciónimportantedesucapacidadreal comopara crearconocimiento.

A me nu do se nos ha pre pa ra do para acep tar, sin dis cu sión, la in for ma ción que se nos trans mi te, sin ani marnos a cues tio nar su validez. He mos falla do en en se ñarleal alum no a pen saren for ma cla ra y crí ti ca, a va lo rar la ló gi ca ola exac ti tud de la in forma ción o a dis tin guiren treloútilylo su per ficial. Nos hemos acos tumbradoa to mar de cisio nes ba sa das en me ras opi niones y no en he chos cier tos, o sim plemen te a "bajarin forma ción" deIn ternet sin crite rios de se lec ción, y a con si de rarla como si fuera unaverdadcomprobada.

Granpartedenuestros es tudiantes, aunhoy, con sideran quelaeducacióncon cluye al recibirsutítulouniversi ta rio. La educación enla era del co no cimien to debeproporcio nar téc ni cas de re fle xión sin las cua les no es po si ble apren der. Comola vida es básicamente aprendizaje, la infraestructura educativa debería ofrecer técnicas esenciales que nos ayudaran a tener éxito en la vida: fortalecer nuestra autoestima; ayudarnos a crear hábitos de apren dizaje, es tu dio, au to disciplina, y a sa berdis tribuir el tiempo; capacitarnosparaestablecerprioridades, dis tinguirentrelourgenteyloimportan te; e infundirennosotrosunprofundodeseoparaaprenderysercompetitivos.

Finalmente, si queremos ser competitivos en la era del conocimiento debemos de volvernosexpertos, peroparaelloesimprescindibledesarrollaryemplearca pacidades que nos ayu den a cap tary asimilarlain forma ción. Elcomplejoproceso deleerpro ductivamenteylacapacidaddeconcentraciónyelsaberescucharsontambiénbásicos.

Debemos aprender a movernos dentro de este creciente volumen de información. paralocuales nece sario familiarizarseconladiversidad de fuentes es pe cíficasy confiablesdein forma ciónydominarlastécnicasdeaccesoaellas. Yconoceraquellas capacida desy técnicas delpensamiento (análisis/síntesis) quenosayu dana convertir volúmenesapreciables deinformaciónenconocimiento, herramientaindispensable para to mardecisionesapropiadasenlas diferentesáreas dedesempeño profesionaly personal,yquenosayudaa evitaroresolversituacionescríticas.

Igualmentedebemosdesa rrollarlascapacidadespersonalesquenospermitancomunicarnos con propiedady transferirconocimientos. Para elloes in dispen sabledesarrollarlahabilidadointeligenciaintraperso nalymanejarlas relacionesinterpersonales. Esto a su vez nos facilita el aprendizaje de las técnicas de comunicación por excelencia:laex presión oralyla escrita.

\section{Comentario 4}

Enla era delages tión del cono cimien to, lo quelaspersonasapren denypue denapren der, así como el desarrollo del intelecto profesional son elementos más valiosos que cualquier otrore cur so dela orga niza ción. Tam bién es cier to quelage ren cia del co no ci mien to es responsabilidad y tarea compartida. Sin embargo, debe formarse personal cuya función central sea la de fomentar, extraer, integrar, editar y transferir el conocimien to de quie nes lo po sean a todo nivel de eje cu ción. Tan to el apren di zaje como el 
conocimien to de benconcebirse comore cursos alservicio delos obje tivosdelas orga ni za cio nes. En tal sen ti do, todo lo que apren da mos de be ría ser acor de con la prác ticaprofesional.

Se gún Quinnet al 24 eléxi to deuna em pre sa seen cuen tra más en susca pa cida des intelectuales yenlas de sus sis te mas que en sus activos físicos. La capacidad paragestionarelin telec to huma noy conver tirlo en pro duc tos y serviciosútiles, se estáconstitu yen do ya enla técnica direc tiva esencial dela épo ca. Como con secuencia, ve mos refle ja do, tan to en la prác tica como en la li te ra tu ra, un gran in te rés en el ca pi talintelectual, la creatividad, la innovación y la organización que aprende. Sin embargo la aten ción pres ta da a lagestióny desarrollo delintelectoprofesional es me nor, lo cual sor prende, ya que el in telec to pro fe sional crea la ma yor par te del valor en la eco no mía ac tual delconocimientoylosservicios.

Observamos queno es capaa esta consideración elprofesionaldelabibliotecología y servicios dein formación, área que re flejauna es casa preo cu pa ción porin ves tigaryen con trarres puestas a cues tiones bási cas como: la na tu ra le za delintelecto profesional, las maneras de desarrollarlo,y la forma de po derlopoten ciar. El au tén tico pro fe sional dis po ne de un con jun to de cono cimien tos y una dis ciplina que debeactualizarenformapermanente.

Además el intelectoprofesional de una organización opera, en orden as cen dente, en cua tro niveles.Los primeros tres niveles, de abajo hacia arriba, re siden en el ce re bro delprofe sio nal, pero también pue denes taren los sis temas, ba ses de da tos o tec nologías ope ra tivas de una or ga niza ción, mien tras que el cuar to ni vel se en cuen tra habitualmenteenlaculturaorganizacional (Cuadro1).

Elcuadronosmues traque elvalor delintelec toprofe sionalau menta ame didaque uno as cien de en la es ca la in te lec tual des de el conocimientocognoscitivo has ta la creatividad automotivada. Sin embargo, según estos autores, gran parte de las organizaciones le otorganuna aten ción prio ri ta ria al de sarrollode técnicas básicas (a cos tadelas avanzadas),peropocaoningunaatenciónalossistemasoalas técnicascreativas.

El profesional de la bibliotecología y ciencias de la información debe adoptar, pues, una ma yoraper tu ra en cuan to al tra ba jo y apo yar los ob je tivos dela orga ni zación, a la vezque de sa rrollar sula borconbase en con cep tos yequiposinter dis ciplinariosy multi dis ciplina rios. Estepro fesional, aligual que otros, tra dicionalmentese ha ro deado de personas con las cualescomparte educa ción, valores ymane ras dehacer las co sas. Sin embargo, ac tual men te se re quie re de un profe sio nal que pue da abrirse de tales círculos basadosenladisciplina, para evi tarserparte de bu ro cra cias ais la das, re sisten tesalcambio yquese hanaleja do delos problemas ynecesidades dela clientela, y,sobretodo, quehanperdidooportunidadesdedesarrolloprofesional.

24 J.B. Quinn,P.Anderson, S. Fin kels tein,2000. “Lages tión del in telec to pro fe sio nal: s a car el má ximo delos mejo res”, en Harvard Bu si ness Re view: Gestión delconocimiento. Bilbao, Es paña. Deus to. pp: 203-230. 


\section{Cuadro 1}

Niveles en que funciona el intelectoprofesional de una organización

\begin{tabular}{|c|c|}
\hline $\begin{array}{l}\text { Niveles de la escala } \\
\text { intelectual }\end{array}$ & Descripción \\
\hline $\begin{array}{l}\text { 4.Creatividadautomotivada } \\
\text { (In te rés en elporqué) }\end{array}$ & $\begin{array}{l}\text { Con sis te de volun tad, mo ti va ción y adap ta bili dad para eléxi to. Gru pos } \\
\text { mo tiva dos y crea ti vos suelen su pe rar a otros con más re cur sos hu ma nos } \\
\text { o eco nó mi cos. Las orga ni za cio nes que ali men tan la in cli na ción ha cia'el } \\
\text { por qué’ en tre su per so nal pue den pros pe rar, si mul tá nea men te, a la vis ta } \\
\text { de los rá pi dos cam bios ac tua les y re no var tan to sus co no ci mien tos cog } \\
\text { nos ci tivos, como las téc ni cas avan za das y los co no ci mien tos de los sis te- } \\
\text { mas para po der com pe tir en la si guien te olea da de ade lan tos. }\end{array}$ \\
\hline $\begin{array}{l}\text { 3. Cono cimien to delos sis te mas } \\
\text { (Know why = Sa berpor qué) }\end{array}$ & $\begin{array}{l}\text { Conocimiento pormeno riza do de la red de re la ciones cau sa- e fec to que } \\
\text { sub ya cen tras una dis ci pli na. Le per mi te al pro fe sio nal so bre pa sar la eje- } \\
\text { cu ción de ta reas, so lu cio nar pro ble mas com ple jos y crear un va lor su pe- } \\
\text { rior. "Sa ber por qué" pue de pre ver re la cio nes su ti les y con se cuen cias no } \\
\text { de sea das. La ex pre sión úl ti ma del co no ci mien to de los sis te mas es una in- } \\
\text { tui ción de enorme califica ción que per mi tesa berins tin tiva men te el cur so } \\
\text { de ac ción de una in ves tiga ción o de un pro yec to. }\end{array}$ \\
\hline $\begin{array}{l}\text { 2. Conocimientosprácticos } \\
\text { avanzados } \\
\text { (Know how }=\text { Sa ber cómo) }\end{array}$ & $\begin{array}{l}\text { Con ver tir el apren di za je de tex tos en apli ca ción efi caz. La ca pa ci dad de } \\
\text { apli car las re glas bá si cas de una dis ci pli na a los pro ble mas com ple jos de la } \\
\text { realidad es el grado de des tre za pro fe sio nal más gene ra liza do en cuan toa } \\
\text { la crea ción de va lor. }\end{array}$ \\
\hline $\begin{array}{l}\text { 1. Conocimientocognos citivo } \\
\text { (Know what }=\text { Sa ber qué) }\end{array}$ & $\begin{array}{l}\text { Do miniobá sico de una dis ciplina ad qui rido por forma ción y certifica ción. } \\
\text { Cono cimien to esen cial aun que, a menu do, no su fi cien te para el éxi to. }\end{array}$ \\
\hline
\end{tabular}

Fuente: Cuadroelaboradoy ajus ta doconbase en el tex to de Quinnet al.(2000).

Coincidiendo con el cua dro 1, una delas ma ne ras más efi ca ces de de sa rrollar el "sa ber cómoprofesional"esmediantelaconstanteyrepetidaexposiciónalacomplejidaddelos problemasimpues tos porlarea lidad.Ejemplodeestetipodeexposición sonlasacciones de consultoría, la elaboración de estudios de diagnóstico, la elaboración y presentación deproyectos, ylaprepa racióndeinstrumentos decoordinaciónycapacitación.Lacurva deaprendizajedeunaimportanteproporcióndeprofesionalesdependerá,enespecial, de sus rela cio nes con laproblemáticaylas necesida des delos clien tesindividualese ins titur cionales. Este tipo de aprendizaje y desarrolloprofesional puedeacelerarsemedianteel apoyoosupervisióndeuntutoropersonamásexperimentada. 
También mediante programas de instrucción apropiados, el profesional puede de sarrollarunmejorconocimien to del 'saberpor qué, es de cir, de las re la cio nes en tre los sis te mas, eiden ti ficarse me jor con la orga niza ción, su mi sión y obje tivos: "inclinaciónhaciaelporqué".

...cam biemos la idea de con side rarnos como
individuos aislados, que buscan cada uno por
sucuen ta supropio bie nes tar, más bien culti-
vemos la idea de encajar en el entorno social,
biológicoyfísico...
R. Ornstein y P. Ehrlich

\section{REFERENCIAS}

Albritton, Ro sieL, 1990. “Con tinuing pro fes sional edu ca tion: a ma nagement development approach", en The Reference Librarian 30: 237-255.

Arboleda-Sepúlveda, O, 1981. "Responsabilidad profesional en la produccióndelaliteraturabibliotecológica”, en Revista AIBDA2(1):49-52.

Arboleda-Sepúlveda, O, 1990. "El cambio en las pers pec tivas del uso de los sistemas y servicios es pecializa dos dein formación en AméricaLatina y el Caribe", en Revista Interamericana de Bibliotecologia (Colombia) 13(2): 61-81.

--,1995. “El proce so de re visión y edi ción de ar tículos para re vis tas deinterés profesional”, en Revista AIBDA 16(1):86-99.

- -, 1995. "Las necesidades de información sobre manejo integrado de plagas; evalua ción de un servicio de alertain forma tiva”, en ManejoInte grado de Plagas (Costa Rica) n 33:28-35.

--,2003. “Iden ti dad pro fe sio nal en la eco no mía de la in for ma ción: el pa peldelColegio deBibliotecarios", en RevistadeBibliotecologiay Cienciasde la Información (Organo de difusión, Colegio de Bibliotecarios de Costa Rica) 17(1/2):6-23.

- -, 2003. "La bibliotecología y ciencias de la información agrícola en la economía de servicios, un análisis dentro de un contexto cambiante", en ReuniónNacionaldeBibliotecarios, $37^{a}$,JornadadeBibliotecas Agropecuarias y Veterinarias, 10 ${ }^{a}$. Buenos Aires, Argentina. 14-17 abril, 2003. 15p.

Drucker, P, 1999. Los de safíos de la administración en elsigloXXI. Bue nos Aires, Sudamericana. 229p.

- -, 2002. La gerencia en la sociedad futura. Bogotá, Norma. 290p.

Gel fand, J, 1985.Professionaldevelopmentforreferenteandadultserviceslibrarians. $\mathrm{RQ}$ (Summer):403.

Jericó, Pilar, 2001. Gestión del talento. Madrid. Prentice-Hall. 176p. 
Levy-leboyer, Claude, 2002. Gestión de las competencias. Barcelona.Gestión 2000. 161p.

McCarthy, M.J., 1991. Domine la era de la información. Barcelona. Robinbook. 301p.

Martin, J., 2001. "La creación de la corporación cibernética”, en Leer, Anne. Comp. Lavisión de los lí de resen la era digital.México,D.F., Pearson Educación. pp.324-332.

Probst, G., Raub, S., Romhardt, K., 2001. Administreelconocimiento. México, D.F. Pearson Educación. 368p.

Quinn, J.B., An der son, P., Fin kels tein, S., 2000. “La ges tión del in telec to profesional: sacar el máximo de los mejores”, en Harvard Business Review: Gestión del conocimiento. Bilbao, España. Deusto. pp: 203-230.

Ray, M.L., 1993. "Surgimiento del nuevo pa ra dig ma en los ne go cios", en Renesch, J. ed. Nuevas tradiciones en los negocios. México, D.F. Panorama Editorial. pp.39-51.

Robbins, S.P., 1998. Fundamentos de comportamiento organizacional. México, D.F. Prentice-Hall. 303p.

Rockman, I.F., 1989. Promoting professionaldeve lopment: Alocalapproach. College and Research Libraries News 50(11):902-904.

Senge, P. M., 1995. La quinta disciplina. Madrid. Granica. 490p.

Taps cott, D., 1996. The digitaleco nomy: Pro mi se endpe rilin the age of networked intelligence. New York. McGraw-Hill.

Tapscott, D., 1998. Creciendo en un entorno digital, la generación net. Bogotá, McGraw-Hill. 304p.

White, G.W., 2001. "The professional development of reference librarians: implications of research, publication and service", en Mabry, C.H. ed. Doing the work of refe rence:practicaltipsforexcelling as a refe rencelibra rian. The Haworth Press, 2001. pp 337-350.

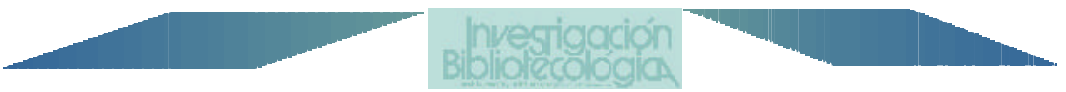

